\title{
Scar Symptoms: Pruritus and Pain
}

\author{
Osama Farrukh and Ioannis Goutos
}

\section{Contents}

\subsection{Pain: Definition and Subtypes - 88}

\subsection{Pain Pathway - 88}

10.2.1 Peripheral Receptor Activation - 88

10.2.2 Ascending Pathway - 88

10.2.3 Descending Pathway - 88

10.2.4 Peripheral Sensitization - 89

10.2.5 Central Sensitization - 90

10.2.6 Pruritus: Definition and Subtypes -90

10.2.7 Pruritic Pathway - 90

10.2.8 Peripheral Nerve Fibers (PNF) - 91

10.2.9 Spinal Cord/Itch Specific Neurons - 91

10.2.10 Thalamocortical Level - 91

10.2.11 Non-pharmacological Adjuncts - 93

10.2.12 Transcutaneous Electrical Nerve Stimulation (TENS) - 94

10.2.13 Pharmacological Adjuncts - 94

10.2.14 Emerging Modalities - 96

\subsection{Conclusion -97}

References - 98 


\subsection{Pain: Definition and Subtypes}

Pain is defined as a distressing sensory experience associated with potential or actual tissue damage with cognitive, emotional, and social components [1]. Pain can be classified into acute and chronic, based on the duration of symptoms as well as nociceptive and non-nociceptive subtypes with regards to the neurophysiological processes involved.

Acute pain is the predicted physiological response to an adverse mechanical, thermal, or chemical stimulus and most frequently occurs after traumatic injury/ surgery as part of the inflammatory response. Chronic pain is defined as pain lasting for three or more months showing no resolution to treatment [1].

Nociceptive pain can be defined as pain arising from the sensitization/activation of peripheral nociceptors and will only continue if the inciting stimulus is maintained [2]. Non-nociceptive pain can be classified into neuropathic and psychogenic pain. Neuropathic pain denotes a primary anatomical or biochemical abnormality arising within the CNS, resulting in persistent and chronic sensory disturbance following the initial injury [3]. It occurs as a result of damage to neural tissue in peripheral and central nervous system and relates to aberrant somatosensory processing. While a detailed account of psychogenic pain is outside the remit for this review, we will elaborate extensively on neuropathic phenomena since they are frequently observed in scar practice.

\subsection{Pain Pathway}

\subsubsection{Peripheral Receptor Activation}

Specialized sensory nociceptor fibers in peripheral tissues are activated by a broad spectrum of stimuli including mechanical, thermal as well as chemical with the most frequent being acetylcholine, bradykinin, adenosine triphosphate, and prostaglandins [4].

\subsubsection{Ascending Pathway}

First-order neuron pathways are responsible for carrying impulses to the dorsal column initially and then other parts of the CNS as part of the ascending pathway and comprise the following different subtypes [5].

A-beta fibers: These are low stimulation threshold, myelinated fibers, activated by vibration and touch; under normal conditions, they convey nonpainful stimuli; nevertheless, they play a crucial role in carrying painful sensations in chronic neuropathic pain.

A-delta fibers: These thinly myelinated fibers have a high threshold potential and are involved in the initia- tion of the reflex response associated with painful stimuli; they transmit pain faster than unmyelinated $\mathrm{C}$ fibers and contain the neurotransmitter L-glutamate.

C-fibers: These fibers are unmyelinated, have a high threshold for activation, and their stimulation causes delayed perception of pain that is often described as diffuse stabbing or burning. As well as glutamate, they contain other neurotransmitters like substance P (SP) and calcitonin gene-related peptide (CGRP).

Second-order neurons start from the dorsal horn and cross over to the contralateral side of the ascending spinothalamic tract to reach the thalamus and pons. The components of the dorsal horn involved in nociception express several receptors including $\alpha$-amino- 3 hydroxy-5-methyl-4-isoxazolepropionic acid (AMPA), voltage-gated calcium channels, N-methyl-D-aspartate (NMDA), as well as gamma-aminobutyric acid-alpha (GABA-A) receptors [4].

Third-order neurons start at the thalamus and end at a number of different cerebral loci.

Processing regarding the magnitude and spatial characteristics of painful stimuli is provided by the somatosensory cortex and the ventral posterior thalamic nuclei. At the same time affective and motivational aspects of pain are processed by the ventromedial posterior thalamic nucleus and its cortical connections [6].

Furthermore, positron emission tomography studies have proposed that pain-related activation of anterior cingulate cortex (ACC) has a direct relationship with an individual's emotional and behavioural reactions to pain [7]. Midbrain periaqueductal gray matter, the region responsible for fight or flight response has also been shown to have interconnections with the ACC [8].

\subsubsection{Descending Pathway}

The dorsal horn of the spinal cord receives input from higher centers, which can modulate the peripheral nociceptor input barrage by the descending pathway.

The descending pathway starts at the limbic system of the brain area, namely the periaqueductal gray/parabrachial area, rostral ventromedial medulla, and nucleus raphae magnus, whose stimulation, in turn, inhibit nociceptors in the laminae of the spinal cord. Key transmitters involved include noradrenaline, serotonin, as well as endogenous endorphins and encephalins [9].

Aside from descending signals, nociceptive impulses can also be modulated by segmental input from A-beta fibers under the gate control theory of pain. In other words, non-nociceptive fiber signals carried by the large diameter A fibers can interrupt the transmission of pain indirectly by inhibiting the effect of pain fibers ("closing the gate") [10]. 

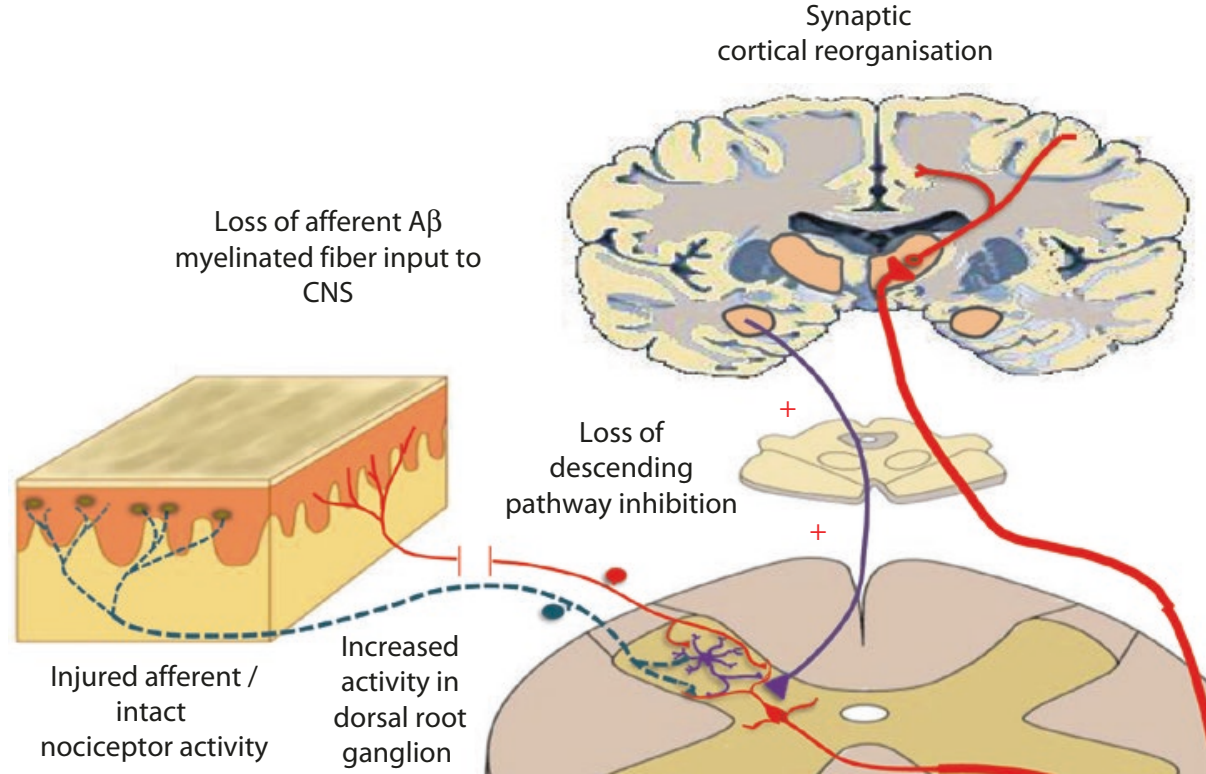

Loss of descending pathway inhibition

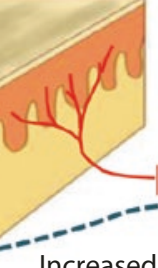

Increased activity in dorsal root ganglion

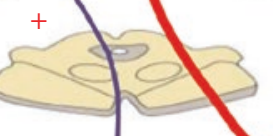

$+$

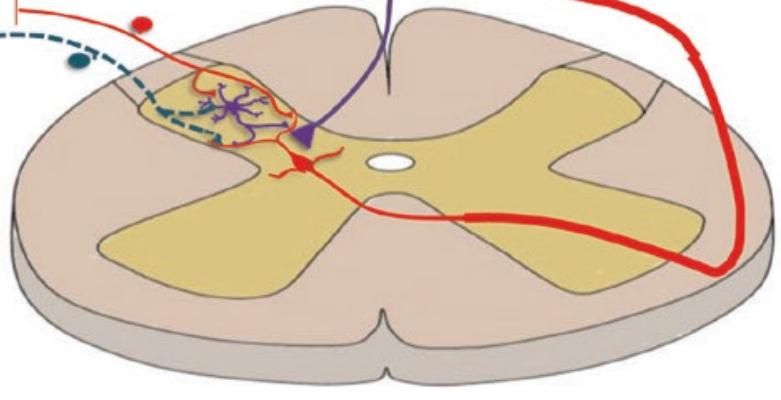

Degeneration of inhibitory CNS neurons

- Fig. 10.1 Schematic diagram of several mechanisms of peripheral and central nervous system neuropathies. Peripheral sensitization include injured afferent hypothesis when a neuroma formed by injury to peripheral afferent fibres causes increased sesitvity to different stimuli resulting in abnormal excitability [11]; intact nocioceptor hypothesis in which spontaneous activity may develop in the nocioceptors that survived peripherally after injury innervating the region of the transected nerve secreting agents altering the activity of uninjured afferents [12] Central sensitization include increased activity in of the dorsal horn projection neurons in the dorsal root ganglion after a peripheral nerve injury causing the release of excit-

Neuropathic pain refers to a type of non-nociceptive pain, which has many neurophysiological phenomena central to its genesis and symptom maintenance. These can involve the central nervous system primarily or secondarily due to changes to the peripheral nervous system components (sensitization). - Figure 10.1 provides a pictorial representation of key processes involving the peripheral and central nervous system in neuropathic states.

\subsubsection{Peripheral Sensitization}

Different mechanisms have been proposed for the occurrence of abnormal signals in the peripheral nervous system capable of ultimately sensitizing the central system, including: atory neurotransmitter glutamate [13]; loss of $\mathrm{A} \beta$-myelinated fibers input causing loss of afferent inhibition resulting in more noxious stimuli reaching the CNS (Deafferentation theory) [14]; degenration of inhibitory CNS neurons (GABA interneurons) in the dorsal horn resulting in decreased inhibtion of nociceptive pathways causing chronic pain [15]; loss of anti-nociceptive descending pathways resulting in increased excitability to the CNS resulting in increased pain [16]; abnormal cotical input as a result of misdirected axonal growths at the site of injury causing reorganization of the somatosensory cortex with distorted skin mapping of the area innervated by the injured afferent [17]

- Injured afferent hypothesis: According to this theory, a neuroma formed by injury to the peripheral afferent fibers causes growth of unmyelinated C fibers from damaged axons and results in abnormal excitability. This spontaneous activity occurs due to increased sensitivity to mechanical, chemical, and thermal stimuli [11, 12].

- Intact nociceptor hypothesis: This concept proposes that intact nociceptors (i.e., those surviving the original injury in the periphery and innervating the region affected by the transected nerve fibers) develop spontaneous activity [11]. Changes in ion channels, expression of receptors, and secretion of agents like prostaglandin, bradykinin, and tumor necrosis factor-alpha have the potential to sensitize nociceptors, thereby altering the properties of uninjured afferents [12]. 


\subsubsection{Central Sensitization}

The following mechanisms have been proposed to underlie central sensitization:

- Increased activity of dorsal horn projection neurons: There is an upregulation of $\alpha_{2} \delta$ subunit of calcium channels in the dorsal root ganglion and spinal cord after a peripheral nerve injury; this results in increased release of excitatory neurotransmitter glutamate [13].

- Deafferentation theory (loss of afferent inhibition): Tissue injury causes loss of $\mathrm{A} \beta$-myelinated fibers input, which is the primary mechanism promoting hypoactivity of interneurons. These interneurons primarily inhibit nociceptive afferents resulting in more noxious stimuli reaching the CNS centers [14].

- Loss of CNS inhibitory neurons: $\gamma$-Aminobutyric acid (GABA) interneurons in the dorsal horn nerve fibers undergo degeneration, causing decreased inhibition of the nociceptive pathway contributing to chronic pain and hypersensitivity [15].

- Loss of descending inhibition: Inhibition of the anti-nociceptive descending pathways can result in increased excitability of the CNS, and this is thought to cause loss of sensory input following peripheral nerve injury [16].

- Synaptic reorganization: Acute deafferentation in the nervous system is thought to stem from peripheral nerve transection resulting in a misdirected axonal growth at the site of injury and cause abnormal cortical input. This mediates somatosensory cortex reorganization with distorted skin mapping originally innervated by the injured afferent [17].

The sensitization phenomena described above appear to play a key role in the generation and maintenance of chronic sensory phenomena in burn scars (see the following section) as well as keloid scars. It is interesting to note that the clinical profile of symptoms in keloids is such that pain in keloid is felt at the center while itch is mostly felt at the periphery raising the suspicion of a small fiber neuropathic state. Its severity has been suggested to correlate with pruritic intensity with a disproportionate number of regenerating unmyelinated $\mathrm{C}$ fibers at the periphery causing itch. Keloids with itch have also demonstrated an overall lower epidermal innervation density pointing toward mechanisms of peripheral nervous sensitization [18, 19]. Another study reporting a large number of thinner nerve fibers in deeper layers of keloidal skin has hypothesized the presence of the intensive fibrous compression (entrapment neuropathy) accounting for painful symptoms [20].

\subsubsection{Pruritus: Definition and Subtypes}

Pruritus is derived from the Latin word prurio, which means "to itch" and can be defined as the unpleasant sensation, which leads to the desire to scratch [21]. It can be divided into acute and chronic as well as into different subtypes based on the pathophysiological processes involved. In terms of chronicity, the acute itch has been proposed to last up to 6 months postinjury/insult to the skin in burns patients, corresponding to the early remodeling phase of wound healing [22]. Pruritic sensations in the healing wound could potentially be explained on the basis of histamine release as part of the inflammatory response and partly by virtue of abundant mast cell present in hypertrophic scars [23]. Nevertheless, the persistence of these symptoms beyond the wound healing and into scarring phase could not be solely explained on a histaminergic basis (see below).

Twycross et al. [24] has classified pruritus into the following four main subtypes:

- Pruritogenic: Arising in the skin because of injury/ inflammation

- Neuropathic: Stemming from within the afferent neurologic pathway

- Neurogenic: Having a central nervous system origin in the absence of neurologic pathology

- Psychogenic: Associated with psychiatric conditions

While a number of non-skin pruritic disorders may appear to consistently fit in one discreet category, the scar-related itch is thought to have a number of nonpruritogenic origins.

\subsubsection{Pruritic Pathway}

\subsubsection{Peripheral Receptor Activation}

A wide variety of substances have been implicated in the generation and propagation of antegrade pruritic stimuli including:

\section{Histamine}

A number of histamine receptors have been described in the literature. The surface of sensory nerve endings have $\mathrm{H} 1$ and $\mathrm{H} 2$ receptors that are activated by histamine stored in the keratinocytes and mast cells [25]; H3 and $\mathrm{H} 4$ receptors are also found on peripheral and central neurons regulating neurotransmitter release and mast cells $[26,27]$. As a by-product of collagen production, histamine synthesis is increased in the healing wound, and this can account for the generation of pruritic stimuli in the healing wound/freshly formed scar [28]. 


\section{Acetylcholine}

Human keratinocytes have been shown to synthesize, store, and release acetylcholine, which, through the activation of M3 muscarinic receptors in the skin, can produce an itch-associated response $[29,30]$.

\section{Bradykinin}

Histamine release can be caused by bradykinin secretion through mast cell degranulation [31]. It also stimulates the release of calcitonin gene-related peptide, substance $\mathrm{P}$, and prostaglandin E2 at the site of tissue injury resulting in inflammation [32].

\section{Proteinases}

Dermal mast cells synthesize proteinases, including tryptase and chymase, which interact with proteinaseactivated-receptor- 2 located on $\mathrm{C}$ fibers neurons, contributing to impulse generation [33].

\subsubsection{Peripheral Nerve Fibers (PNF)}

A specific group of "unmyelinated C fibers" appears to be responsible for the transmission of itch; they start at the dermo-epidermal junction and reach the spinal cord via the dorsal root ganglion. These fibers have a characteristic slow conduction velocity $(0.5 \mathrm{~m} / \mathrm{sec})$ with a prolonged histamine response and extensive terminal branching. The main transmitters released include substance $\mathrm{P}$ and calcitonin gene-related peptide [34].

\subsubsection{Spinal Cord/Itch Specific Neurons}

Andrew and Craig, in their experiments on cats, showed "itch-specific" neurons to be located in the superficial part of the dorsal lamina I of spinothalamic tract [35]. They are characterized by their lack of ongoing discharge and low conduction velocities and terminate at the thalamus before crossing over to the contralateral side in the spinal cord.

\subsubsection{Thalamocortical Level}

The exact parts of the brain activated by the pruritic pathway are still not fully characterized; lamina I of the spinothalamic tract was originally postulated to terminate in the medial dorsal and ventral medial nucleus of the thalamus in primates [36]. However, positron emission tomography studies have failed to show any subcortical activation in healthy individuals and instead show significant activation in contralateral somatosensory cortex and in both ipsilateral and contralateral motor areas (premotor cortex, primary motor cortex, and supplementary motor area). The cingulate gyrus and prefrontal cortex have also been implicated in neuronal transmission and this may potentially be the reason for the associated emotional component seen in scratching behaviour of patients suffering from pruritus [37].

The generation and maintenance of pruritic symptoms into a chronic state has been postulated to relate to a state of central nervous system sensitization, based on a combination of clinical, neurophysiological, as well as pharmacological data [38]. The salient observations supporting a neuropathic state in chronic pruritus in burns patients are summarized below.

(a) Emerging pharmacological evidence behind the effectiveness of antihistamines at different timepoints during rehabilitation indicates that in the later phases of healing, wounds and scars become unresponsive to antihistamine therapy [39, 40, 41]. This may point toward the involvement of the central nervous system in the maintenance of these symptoms and is further supported by the superiority of centrally acting agents including gabapentin and pregabalin $[34,35,42,43]$ and transcutaneous electrical nerve stimulation modalities in symptom management [41, 44].

(b) Neurophysiological studies in burn scars show that phenomena similar to those occurring in chronic neuropathic pain exist in terms of the presence of increased sensitivity to stimuli (hyperalgesia/hyperkinesis) on the background of otherwise overall decreased sensibility. This finding provides some evidence of possible deafferentation as a mechanism for CNS sensitization [44, 45].

(c) Clinical presentation highlights a pattern of symptom exacerbation at night time, which is found typically in neuropathic states [46, 47].

(d) The neurological pathways of both symptoms share common features including the role of substance $\mathrm{P}$ and CGRP as well as similar areas of the central nervous system activated in the generation of symptoms as in neuropathic pain [48, 49].

(e) Neuropeptide expression data. Hypertrophic scar biopsies in patients with pain and itch demonstrated a higher density of neuropeptides (SP and CGRP) compared to controls, whereas these were absent in non-hypertrophic scars providing a link between neuropeptide expression and impulse transmission. Interestingly, SP immunoreactivity was present in the densely packed areas of scar hypertrophy [50].

Another study in grafted burn skin showed the coexistence of overall decrease in axonal population and a preferential increase in SP fibers correlating with pruritic symptoms; this provides a link between a state of SP hyperinnervation in a milieu of deafferentation possibly leading to a neuropathic state [32]. Furthermore, neuropeptides like SP are thought 
to play a key role in perpetuating fibroproliferative pathology establishing a cycle of nociception and scar hypertrophy [50, 51].

Other authors have proposed the role of opioids in the generation of pruritic impulses in hypertrophic burn scars [52].

\subsubsection{Incidence/Prevalence of Pain and Itch in Scars}

Pain is a major sensory disturbance and has been described as contributing to the "hidden cost" of cutaneous scars. According to a study based on semi-structured interviews in a UK scar specialist service, it has been identified that $26 \%$ and $44 \%$ of patients reported pain and itch in association with their scars, affecting their physical comfort and functioning [53].

In a corroborative study, pain and itch have been found to correlate with physical impairment $(P \leq 0.001)$ in a study of 100 patients with keloid and hypertrophic scarring attending a German dermatology department using the Questionnaire on Experience with Skin Complaints. Similar work utilizing the Dermatology Life Quality Index (DLQI) tool confirmed that keloids have a statistically significant effect on the quality of life compared to physiologic scars $(p<0.001)$; additionally, they are associated with a statistically significant increase in pain and itch disturbances $(P<0.01$ and 0.001 respectively) [54].

A cross-sectional health-related quality of life (HRQL) assessment study focused on indicators of the burden for 106 keloid patients using one disease-specific (Skindex-29) and two generic (SF-36 and EQ-5D-5L) HRQL measures; results indicated that pain and itch were the strongest predictors of impairment and related to low mental and emotional status [55].

A study evaluating chronic pain due to central sensitization in burn scars showed a 35\% prevalence of pain in scarred tissue one or more years after injury [56, 57]. Additionally, work evaluating 98 burn survivors, reported $25 \%$ of patients having painful scars and $20 \%$ experiencing shooting pain more than 30 years postinjury [21]. A retrospective review involving 72 patients suggested that the first complaint of neuropathic pain presents on average at 4.3 months after injury and that there is a qualitative progression pattern; symptoms are initially reported as "pins and needles," then being predominantly stabbing or burning pain followed by "shooting" sensory qualities [58].

A multicenter cohort involving 510 patients was used to evaluate the incidence and prevalence of burns itch. In this long-term prospective study, $64 \%$ of individuals reported itch to be a significant problem over a 2-year period. At three months, $87 \%$ of individuals reported severe itching; this fell to $70 \%$ at 12 and $64 \%$ at 24 months respectively. Predictors of itch at three months postburn included total burned surface area (TBSA), female gender, number of surgical procedures (deep dermal injury), and post-traumatic stress disorder (PTSD) symptoms at two weeks post-injury. Interestingly, at 24 months the only predictors for itch complaints were the latter two (PTSD at two weeks post-injury and the presence of deep dermal injury). The authors proposed that acute itch (up to 6 months) corresponding to the early remodeling phase of wound healing effects, both partial and full-thickness burn injuries. Chronic itch, on the other hand, affects patients with certain predisposing factors, providing a link between the chronicity of symptoms and markers of injury severity as well as psychological stress [59].

Another multicenter, large cohort study of adult burn survivors, reported high prevalence and severity of post-burn pruritus. Two cohorts of individual with burns were studied; the first included 637 patients followed prospectively over a 2-year period and identified that pruritus initially affected more than $90 \%$ of individuals and persisted in more than $40 \%$ of burn survivors in the long term. The second cohort comprised 336 patients who sustained burn injury 4-10 years before assessment using the 5-D itch scale. Pruritus was reported as severe in $76 \%$ patients within this group, moderate in $29 \%$, and mild in $52 \%[60]$.

Schneider et al. [61] conducted a retrospective review of 430 pediatric burn survivors with a mean TBSA of $40.8 \%$. Findings included that pruritus is present in most children $(93 \%)$ and is of moderate intensity at discharge. The frequency and intensity of symptoms decreased over time; nevertheless continued to affect $63 \%$ of children at two years post-injury; furthermore, regression analysis showed significant correlations between pain and itch intensity at each time point. Most interestingly, no association was identified between pruritic intensity and burn etiology, age, gender, or burn size.

\subsubsection{Management of Symptoms}

Sensory symptoms in scars can be managed using a variety of approaches; undoubtedly, the most important initial step toward successful management relies on reliable and consistent monitoring of symptoms. A plethora of clinical measurement scales have been described in the literature; some of the most commonly utilized mono-dimensional scales include verbal, visual, as well as numerical analogue scales [62]. Other evaluation methods like the "itch man scale" incorporate a pictorial element, which makes them more suitable for pediatric patients or those unable to complete analogue scales [63]. Multidimensional tools including the 5-D Pruritus Scale have the advantage of incorporating components of the sensory experience other than intensity, including duration and disability, hence offering the opportunity 
to capture the degree of disturbance in a more comprehensive manner [64].

A variety of pharmacological and non-pharmacological adjuncts are available and frequently using a combination of modalities provides an optimal therapeutic approach.

\subsubsection{Non-pharmacological Adjuncts}

\subsubsection{Psychological Support}

A multidisciplinary approach toward treating sensory disturbances in scars is vital, and psychological support has been suggested as an integral part of the management plan [65]. This is particularly pertinent given the association between psychological stress and perseverance of sensory symptoms into a chronic state [38].

\subsubsection{Cooling}

The application of cooling agents as part of wound care and scar management can help temporarily relieve pruritic sensations. The beneficial effect of cooling can be explained by the temperature-sensitive activation of certain excitatory ion channels, including vanilloid receptor 1 as well as ascending pathway $\mathrm{C}$ fibers $[34,66]$.

\subsubsection{Hydration/Moisturization}

Two recent literature reviews have found that there is limited and low-level evidence behind the optimal choice of a moisturizing and hydrating product for burn scars [67], with a small number of studies investigating the value of different products available. The rationale for moisturization of a scar relates to addressing the increased rate of transepidermal water loss (TEWL) seen in scars and potentially inhibits the fibrogenic action of fibroblasts by virtue of the hydrating effect [68].

The ideal moisturizer should have both occlusive as well as humectant ingredients. Occlusive substances (e.g., oils) function to impede water loss, whereas humectants (e.g., glycerin, propylene glycol, etc.) attract water from the dermis into the stratum corneum. The presence of a defective barrier against transepidermal water loss in scarred skin implies that a humectant-only-based preparation would enhance fluid loss, hence should be avoided [69].

A small randomized study has indicated that mugwort lotion is a promising topical agent for the relief of an itch in burns hypertrophic scarring [70]; additionally, a nonprescription moisturizer containing a blend of protease enzymes (Provase) applied every 8 hours for four weeks has been shown to reduce itch severity parameters as well as the affective burden significantly [71].

A similar randomized controlled study among 52 patients with postburn itch found that a preparation of beeswax and herbal oil had a statistically significant better effect on itch compared to aqueous cream
( $P=0.001)$; additionally, symptoms recurred later comparatively $(P \leq 0.001)$, and the use of antipruritic medications was lower $(P=0.023)$ [72].

A different literature report compared the effects of hydrocolloid dressing versus moisturizer in 20 patients with keloid and hypertrophic scars over a 2-month period in a randomized controlled prospective manner. Results indicate that both products achieved a similar reduction in itch $(P<0.03)$ and pain $(P<0.08)$ presumably by virtue of scar hydration [73].

One of the most interesting reports in the literature focused on the comparison between a hydrating gel-cream and three fluid silicones in a group of healthy volunteers. The moisturizer Alhydran (BAP Medical, Belgium) has been found to have an equivalent effect on hydration and occlusion suggesting that these may be the most important in topical scar care preparations as opposed to active substances like silicone, which have become extremely popular in recent decades [74].

\subsubsection{Massage}

Massage has been shown to be effective for the management of pain, itch, and anxiety associated with scars in a number of studies [75-77]. The first randomized study included 20 patients in the remodeling phase of scar formation; these were divided into either a 30-minute massage with cocoa butter to a moderate-sized scar tissue area twice a week for five weeks or standard therapy (cocoa butter application to scars applied by physical therapists without massage motions). The massage therapy group showed reduced pain, itch (both measured using visual analogue scales), as well as anxiety scores consistently throughout the study period [75]. Similar results were obtained in a study with a comparable design with regards to pain, itch, and anxiety in adolescent burn victims [78].

A Korean group investigated the effects of skin rehabilitation massage for three months in a group of 18 burn survivors; this involved the combination of light stroking movements followed by acupressure using oil as a medium applied for 30 minutes once a week for three months. Results indicated a statistically significant improvement of pruritus in the massage group $(t=-2.942, p=0.006)$ as well as depression $(t=-2.920, p=0.007)$ [76]. The underlying mechanisms of action of massage include the principles of the "gate theory" of pain modulation as well as the increased vagal activity, reducing stress hormone levels in the recipient $[10,79,80]$.

\subsubsection{Silicone Gels/Sheets}

Silicone is widely used for the treatment of symptomatic hypertrophic scars. The proposed beneficial mechanisms involved include increased skin hydration (by virtue of occlusion) and a decrease in fibroblastic activity [81, 82]. 
The literature contains a number of high-quality studies regarding the role of silicone for the prevention of hypertrophy including a randomized placebocontrolled, double-blind prospective trial on sternotomy wounds showing a statistically significant effect on pain and itch symptoms [83].

Topical application of silicone gel versus placebo gel has been investigated in a randomized within-subject comparative clinical trial. Results suggested that silicone gel promoted maturation of early burn scars (mean age of scars in the study 4 months) and a decrease in itch symptoms in a statistically significant manner [84]. Similar beneficial effects were reproduced in a different study employing silicone gel application to burns hypertrophic scarring showing a significant difference in terms of scar vascularity starting at the first month of application [85].

Another study utilized silicone gel sheets in the conservative management of six keloid patients for 24 weeks. Symptoms of pain and itch showed a decrease after four weeks of the gel sheeting application and disappeared after 12 weeks. After 24 weeks, a histological decrease in the number of mast cells was observed, which may explain the therapeutic benefit seen by virtue of a decreased concentration of mast cells derived mediators [86].

A number of comparative studies exist in the literature, which aimed to elucidate the role of silicone products in the scar care arena.

A randomized clinical trial of 45 post-traumatic hypertrophic scars found that silicone gel sheeting applied 24 hours/day for six months was superior to 15-minute-long daily massage in reducing scar thickness in a statistically significant manner $(p<0.001)$; of particular note is that pain and itch reduction did not reach statistical significance in this study [87].

A separate prospective single-blinded study compared the efficacy of $585 \mathrm{~nm}$ flashlamp-pumped pulsed dye laser and silicone gel sheeting and control in the management of 20 patients with hypertrophic scars; results showed an overall reduction of blood flow, volume, and pruritus for all the study subgroups but failed to show any statistically significant difference between treatment and control groups [88].

A prospective split sternotomy scar study [89] involving 14 patients randomized to treat one-half of the scar with triamcinolone acetonide (TAC) and the other with silicone gel sheeting worn for 12 hours for 12 weeks. The primary outcome of patient preference was analyzed, and recruitment was terminated after 11 patients had completed the study, 10 of whom favoured silicone gel treatment. The average time for the symptomatic improvement of silicone-treated patients was 3.9 days as compared to triamcinolone acetonide, which was 6.8 days $(p<0.05)$. The authors proposed that the enhanced compliance to silicone-based treatments relates to the painless and noninvasive nature of silicone-based adjuncts.

\subsubsection{Transcutaneous Electrical Nerve Stimulation (TENS)}

TENS involves the application of low-voltage electrical impulses to the nervous system by means of electrodes placed on the skin [90]. The underlying mechanism of action involves the stimulation of rapidly conducting A-fibers, which inhibit the transmission of noxious stimuli carried by the slower $\mathrm{C}$ fibers according to the "gate theory of pain" [10].

A pilot study involving 20 patients with healed burns complaining of severe itch following burns demonstrated a statistically significant change in the reported visual analogue scale compared with placebo over a 3-week period [90].

\subsubsection{Pharmacological Adjuncts}

\subsubsection{Capsaicin}

This is a naturally occurring alkaloid compound, which interacts with the transient receptor potential V1 receptor resulting in the depletion of neuropeptides from peripheral nerves. Despite the fact that capsaicin forms one of the mainstay topical agents in many chronic pain services, a double-blind placebo-controlled randomized trial using $0.025 \%$ capsaicin cream on 30 patients with pruritic wounds revealed no significant effects on pruritic symptom relief [91, 92, 93]. Further work is warranted involving preparations with different concentrations of this agent in order to elucidate its exact role in the management of symptomatic scars.

\subsubsection{Antihistamines}

Antihistamines have traditionally been used as first-line agents for the management of pruritus. First-generation compounds (diphenhydramine, hydroxyzine, cyproheptadine, and chlorphenamine) act on histaminic, serotonergic, muscarinic, and alpha-adrenergic receptors. Second-generation compounds, like cetirizine, have minimal activity on non-histaminic receptors and hence have a more favourable side effect profile as well as a longer duration of action [94, 95]. The pharmacological action of antihistamine relates primarily to a reverse agonist action at histaminic receptors as well a central nervous system sedative effect (the latter action refers to first-generation compounds).

One of the initial studies involving 35 burns patient complaining of severe itching after discharge assessed the efficacy of three first-generation antihistamines, 
namely chlorpheniramine, hydroxyzine, and diphenhydramine. The results of the study pointed toward no significant difference in therapeutic efficacy between the three compounds and only a $20 \%$ complete relief of symptoms in the cohort [96].

\subsubsection{Gabapentin/Pregabalin}

Gabapentin is a useful agent for the management of neuropathic pain associated with a variety of conditions, including post-herpetic neuralgia [97].

The mechanism of action of gabapentin involves a number of mechanisms, including:

1. Blockade of the $\alpha_{2} \delta$ subunits of voltage-gated $\mathrm{Ca}$ channels resulting in a reduced release of excitatory neurotransmitters [98].

2. Increased synthesis and release of $\gamma$-aminobutyric acid in the CNS [99].

A comparative study appraised two different therapeutic protocols for the management of burns pruritus in patients with healing and healed burns in a UK burn center incorporating a mixture of antihistamines and gabapentin; the authors concluded that gabapentin as monotherapy as well as in combination with another two antihistamines was more efficacious compared to chlorpheniramine alone and in combination with another two antihistamines $(t=3.70, \mathrm{df}=89, P<0.001$ for monotherapy and $x^{2}=12.2, \mathrm{df}=1, P=0.001$ for polytherapy). Additionally, patients with higher initial pruritus scores needed a combination of pharmacological agents for effective symptomatic relief. This study raised the value of centrally acting agents in itch management and proposed the combination of peripherally and centrally acting agents in the treatment for burns pruritus [41].

Another landmark study comprised a four-arm, double-blind, randomized and placebo-controlled study of pregabalin in the management of postburn pruritus. Pregabalin is a newer analogue of gabapentin with comparatively better anxiolytic and pharmacokinetic properties. The study compared the following four groups: pregabalin; cetirizine and pheniramine maleate; the combination of pregabalin, cetirizine, and pheniramine maleate; and placebo. Results indicated that for moderate to severe pruritus (VAS 6-10) a centrally acting agent like pregabalin is indicated to significantly decrease itch; patients with milder itch (VAS 4-5) are best served with the addition of pregabalin even if massage and antihistamines can provide some control because of quicker, predictable response with the added benefit of anxiolysis [77].

\subsubsection{Steroids}

Steroid delivery to hypertrophic and keloidal scars is a well-established modality for the alleviation of scarrelated symptoms, including pain and itch, and their beneficial effects were first recorded in literature in the 1950s [100]. The international advisory panel in 2002 recommended triamcinolone acetonide (TAC) as the first-line treatment modality for keloid and second-line treatment for linear hypertrophic scar in reducing subjective symptoms associated with keloid and hypertrophic scar like pain and pruritus [101].

In 2014, a protocol re-evaluation was undertaken, which reinforced the prominent position of steroids in scar management albeit supported a combined approach incorporating the use of other agents including 5 fluorouracil, cryotherapy, laser, and silicone products [102].

Darvi evaluated the use of intralesional triamcinolone acetonide in treating hypertrophic and keloid scars in 65 patients with a 10-year follow-up. The dosage of TAC for $1-2 \mathrm{~cm}^{2}$ of scar surface area was determined to be $20-40 \mathrm{mg}, 40-80 \mathrm{mg}$ for $2-3 \mathrm{~cm}^{2}$, and $60-120 \mathrm{mg}$ for scar surface area of $4-6 \mathrm{~cm}^{2}$. In this study four injections of TAC were given for the total dose delivered to the scar at 1-2-week intervals with an ensuing symptomatic relief seen in $71 \%$ of patients; furthermore, a dramatic improvement of symptoms with full flattening of hypertrophic scars was seen in $50 \%$ and $71 \%$ in patients with keloid scars [103].

Manuskiatti [104] and colleagues performed a randomized controlled trial comparing the effects of intralesional triamcinolone acetonide with 5 -fluorouracil or alone with $585 \mathrm{~nm}$ pulse dye laser. TAC-treated scars had better improvements in clinical symptoms (pain, itching) and scar induration, although the results were not statistically significant. Intralesional triamcinolone acetonide treatment, however, did produce side effects, including skin atrophy, telangiectasia, and hypopigmentation in $50 \%$ of the TAC-treated group. Boutli-Kasapidou and colleagues [105] evaluated a polytherapy protocol, including three triamcinolone acetonide intralesional injections every month combined with 12 monthly cycles of cryotherapy and 12-hour silicone dressing for 12 months. Patient satisfaction scale was used to grade the appearance cosmetically and subjective symptoms (pain, burning, and tension post 12 months). Similarly, an investigator satisfaction scale was used as well. The results showed that compared to monotherapy, polytherapy group had a major improvement in control of symptoms and appearance, reported by the patient and observed by the physician $(P<0.01)$. They concluded the beneficial effects of each treatment acting synergistically: Steroids downregulating the excessive collagen expression in keloids and making it softer, ischemic destruction and subsequent necrosis of keloids with cryotherapy, and silicon downregulating mastocytes.

Tan and colleagues [106] conducted a patientcontrolled prospective study for 12 weeks with patients receiving intralesional triamcinolone acetonide $(40 \mathrm{mg} /$ $\mathrm{mL}$ ), silicone gel sheeting, or no treatment (control). 
The dose of triamcinolone acetonide varied between $0.1 \mathrm{ml}$ to $0.5 \mathrm{ml}$ of $40 \mathrm{mg} / \mathrm{mL}$ of TAC depending upon the size of the lesion. In this trial, $12 \%$ of siliconetreated keloids showed a significant reduction $(>50 \%)$ in size compared with $94 \%$ of triamcinolone acetonide group (RR: 33.00, 95\% CI: 2.14-509.33). There was also a significant improvement in erythema (RR: $21.00,95 \%$ CI: 1.33-332.06). The improvement in itch and pain was not statistically significant when compared to control.

Martin et al. studied the combination of carbon dioxide fractional laser $(10,600 \mathrm{~nm})$, a pulsed dye laser $(585 \mathrm{~nm})$, and triamcinolone acetonide $(40 \mathrm{mg} / \mathrm{ml})$ injections monthly for seven sessions in a cohort of keloid scars; they reported favourable results in regards to pruritic relief [107].

Steroids can also be delivered to scars in the form of tape application. Advantages of this modality include the noninvasive nature and the ability to maintain a continuous level of steroid concentration to the symptomatic scar, which can ameliorate the inflammatory milieu responsible for the bulk as well as sensory symptoms [108].

\subsubsection{Botulinum Toxin}

Botulinum toxin is a protein neurotoxin produced by the spore-forming bacteria Clostridium Botulinum; it works by preventing the release of acetylcholine at the neuromuscular junction and causing chemoimmobilization as well as affecting a variety of cell types including fibroblasts [109]. It is an established adjunct in a variety of medical and aesthetic interventions and over the last number of years has been trialed in the scar management arena. The rationale for its use rests on the ability to decrease muscular tension underlying a scar as well as the ability to alter a host of fibroblast related pathways, including their proliferation and cell cycle [110].

A randomized, double-blind comparative trial [111] involving 24 females with idiopathic or post-traumatic keloids employed the use of either intralesional triamcinolone $(10 \mathrm{mg} / \mathrm{cc})$, given every four weeks for six sessions or $5 \mathrm{IU} / \mathrm{cm}^{3}$ intralesional botulinum toxin every eight weeks for three sessions; in both groups, therapy was continued until complete improvement of keloid was noted. The authors concluded that the effects of intralesional botulinum toxin A comparable to that of intralesional steroids with a significant reduction in volume height and redness of scar in both groups $(p<0.01)$. In the 7-month follow up both treated groups had a statistically significant reduction in subjective symptoms of pain and itching with a statistically significant difference in favour of the botulinum toxin A treated group with the added advantage of no side effects which were typically seen in steroid-treated patients.

Another blind study compared the effect of triamcinolone acetonide (maximum of $40 \mathrm{mg}$ dose) plus pla- cebo versus triamcinolone acetonide and botulinum toxin (20IU) for keloid scars injected every four weeks for a total of 12 weeks. Although the difference in height, vascularization, and the pliability were not significant between the two groups, there was a significant difference in favour of the botulinum group in terms of pain and pruritus control $((p<0.001)$ at the end of the study [112].

Similar results in terms of the superior alleviating effect of botulinum toxin have been reached in another randomized, single-blind study in 32 keloid patients [113].

The use of botulinum toxin has been reported in the burns literature as part of a pilot study involving nine patients, eight of which had skin grafts for deep partial-thickness to full-thickness burns, with an average TBSA of $24 \%$. At the beginning of the study, $87.5 \%$ of patients rated their burns itch as being severe $(>7 / 10)$, which fell to 0 at four weeks following the administration of toxin [114].

Further studies are warranted to delineate the exact role of botulinum toxin in scar symptom management.

\subsubsection{Emerging Modalities}

\subsubsection{Autologous Fat Grafting}

Autologous fat grafting has been widely used for the treatment of contour deformities and increasingly employed to remodel and regenerate tissue by virtue of mesenchymal stem cells present in adipose tissue $[115,116]$.

The proposed mechanism supporting the alleviation of scar symptoms is suggested to relate to the mechanical release of adhesions, neovascularization, and remodeling of scar tissue architecture [117]. Other mechanisms proposed for controlling neuropathic pain symptoms include blockade of nociceptive impulses and an overall reduction of the signal input to the central nervous system [118].

Fredman et al. [119] in a retrospective case review evaluated the effectiveness of fat grafting in neuropathic burn scars using the patient-reported outcome measurement information system (PROMIS) to assess pain following two fat-grafting sessions eight weeks apart. Results showed a statistically significant improvement in subjective outcomes at 1-year follow-up.

Huang et al. [120] evaluated autologous fat grafting in 13 patients with neuropathic scar pain. Pain evaluations were undertaken using the Visual Analogue Scale (VAS) and Neuropathic Pain Symptom Inventory (NPSI) preoperatively and at 1, 4, and 24 weeks postoperatively. Both VAS and NPSI scores showed a significant decrease starting at one week, alleviating neuropathic scar pain in the short term, which were statistically significant $(P=0.009$ and $P=0.007$ 
respectively). The NPSI score continued to decrease at four weeks $(P=0.0009)$ till 24 weeks $(P=0.0008)$ with the most significant improvement in paresthesia, dysesthesia and evoked pain $(P<0.001)$. They concluded the autologous fat provides insulation and acts as a cushion to block abnormal sensations and prevent stimulation.

Two systematic reviews of the literature pertaining to the use of fat grafting and adipose-derived stem cells in scarring have shown improvements in scar characteristics including texture and size, improved pain profiles, increased angiogenesis, and an earlier return to function $[121,122]$. It is clear that the use of fat-derived cells will play an important role in the future of scar treatments in the field of regenerative medicine.

\subsubsection{Lasers}

Laser stands for "Light Amplification by Stimulated Emission of Radiation" and exerts its effect on the tissue through photochemical/thermal/mechanical mechanisms [123].

The photothermal effect or photothermolysis is the most relevant mechanism in scar treatment with the main target being either blood vessels (pulsed dye laser) or water $\left(\mathrm{CO}_{2}\right.$ and Er:YAG laser). Lasers can be further subdivided into ablative and non-ablative based on whether the epidermis is affected or not and fractional and non-fractional: based on whether intact columns of skin are left behind or not after the treatment [124].

Pulsed Dye Laser is a vascular specific laser with haemoglobin being the target chromophore. Selective photothermolysis [125] with a short pulse duration leads to selective absorption of heat by haemoglobin, leading to thrombosis and vasculitis [126].

Ebid et al. [127] in a double-blind, randomized, placebo-controlled trial, compared the effects of pulsed high-intensity laser in the treatment of post-burn pruritus. They showed that a combination of a long period of high-intensity pulsed laser, antihistamine, and massage could effectively control moderate to severe burn pruritus, raising the value of incorporating laser modalities in antipruritic protocols.

Vasheghani and colleagues [128] showed that lowlevel laser therapy in second-degree cutaneous burns decreases the total number of mast cells in the remodeling phase while increasing the number of mast cells in the proliferative and inflammatory phases. Increased level of growth factors and anti-inflammatory cytokines and decreased level of pro-inflammatory cytokines like interleukin alpha and beta have been shown after treatment with laser therapy [129] elucidating potential mechanisms for the action of laser on pruritic pathways. Other proposed mechanisms include the direct action on reactive oxygen species, inhibition of cyclooxygenase
(COX) and prostaglandin E2 [130], as well as the fast axonal flow and microtubule disruption of $\mathrm{A} \delta$ and $\mathrm{C}$ fibers transmission [131].

Alster and Williams [132], in an investigator-blinded split scar study of patients with keloid scarring, performed two sessions of flash pump $585 \mathrm{~nm}$ pulse-dyed laser treatment to half of the scar at 6-8-week intervals. They reported a significant improvement in the texture of the skin surface, scar height, erythema, pruritus with coarse, loose collagen, and increase number of mast cells seen histologically in the laser-treated side.

A prospective randomized controlled trial investigated the outcomes following ablative fractional $\mathrm{CO}_{2}$ laser on 19 patients with burn scars (minimum age of scars for inclusion six months). Results demonstrated that three treatments of ablative fractional $\mathrm{CO}_{2}$ laser (Deep FX setting on UltraPulse ${ }^{\circledR}$, Lumenis; treatment parameters: single pass of $300 \mathrm{~Hz}, 5 \%$ density, and $50 \mathrm{~mJ}$ energy) significantly improved scar pain, itch based on Patient and Observer Scar Assessment Scale (POSAS) scores $(p=0.047$ and $<0.01$ respectively). Additional findings included an improved dermal architecture at six weeks post-treatment [133].

\subsection{Conclusion}

Pain and itch represent the most common sensory symptoms accompanying scars and can have a significant impact on patients' quality of life. Over the last number of decades, our understanding of the pertinent pathophysiological mechanisms has improved considerably, especially with regards to the contribution of the central nervous system in the generation and maintenance of nociceptive and pruritic stimuli. Consistent and reliable monitoring of symptoms combined with a multimodal approach to treatment should be integral parts of holistic scar management.

\section{Take-Home Messages}

- Itch and pain can have a significant impact on individuals with scars.

- The contribution of the central nervous system in the generation and maintenance of symptoms is paramount.

- Accurate assessment and monitoring of symptoms are central to successful scar management.

- Multimodal approaches which target both peripheral and central nervous system components and incorporate non-pharmacological adjuncts are recommended. 


\section{References}

1. Anwar K. Pathophysiology of pain. Dis Mon. 2016;62(9):324-9.

2. Woolf CJ, Bennett GJ, Doherty M, Dubner R, Kidd B, Koltzenburg M, et al. Towards a mechanism-based classification of pain? Pain. 1998;77(3):227-9.

3. Yosipovitch G, Samuel LS. Neuropathic and psychogenic itch. Dermatol Ther. 2008;21(1):32-41

4. Schug SA, Daly HCS, Stannard KJD. Pathophysiology of pain. Mechanisms of vascular disease: a reference book for vascular specialists. Adelaide: University of Adelaide Press; 2011.

5. Woolf CJ. American College of Physicians, American Physiological Society. Pain: moving from symptom control toward mechanism-specific pharmacologic management. Ann Intern Med. 2004;140(6):441-51.

6. Mackey SC, Maeda F. Functional imaging and the neural systems of chronic pain. Neurosurg Clin N Am. 2004;15(3):269-88

7. Rainville P, Duncan GH, Price DD, Carrier B, Bushnell MC. Pain affect encoded in human anterior cingulate but not somatosensory cortex. Science. 1997;277(5328):968-71.

8. Buhle JT, Kober H, Ochsner KN, Mende-Siedlecki P, Weber J, Hughes BL, et al. Common representation of pain and negative emotion in the midbrain periaqueductal gray. Soc Cogn Affect Neurosci. 2013;8(6):609-16.

9. Stamford JA. Descending control of pain. $\mathrm{Br}$ J Anaesth. 1995;75(2):217-27.

10. Melzack R, Wall PD. Pain mechanisms: a new theory. Science. 1965;150(3699):971-8.

11. Campbell JN, Meyer RA. Mechanisms of neuropathic pain. Neuron. 2006;52(1):77-92.

12. Truini A, Cruccu G. Pathophysiological mechanisms of neuropathic pain. Neurol Sci. 2006;27(S2):s179-82.

13. Kusuyama K, Tachibana T, Yamanaka H, Okubo M, Yoshiya $\mathrm{S}$, Noguchi K. Upregulation of calcium channel alpha-2delta-1 subunit in dorsal horn contributes to spinal cord injuryinduced tactile allodynia. Spine J. 2018;18(6):1062-9. https://doi. org/10.1016/j.spinee.2018.01.010.

14. Zimmermann M. Pathobiology of neuropathic pain. Eur J Pharmacol. 2001;429(1-3):23-37.

15. Scholz J, Broom DC, Youn D-H, Mills CD, Kohno T, Suter MR, et al. Blocking caspase activity prevents transsynaptic neuronal apoptosis and the loss of inhibition in lamina II of the dorsal horn after peripheral nerve injury. J Neurosci. 2005;25(32): 7317-23.

16. Porreca F, Ossipov MH, Gebhart GF. Chronic pain and medullary descending facilitation. Trends Neurosci. 2002;25(6): $319-25$.

17. Oaklander AL. Mechanisms of pain and itch caused by herpes zoster (shingles). J Pain. 2008;9(1):10-8.

18. Tey HL, Maddison B, Wang H, Ishiju Y, McMichael A, Marks $\mathrm{M}$, et al. Cutaneous innervation and itch in keloids. Acta Derm Venereol. 2012;92(5):529-31.

19. Lee S-S, Yosipovitch G, Chan Y-H, Goh C-L. Pruritus, pain, and small nerve fiber function in keloids: a controlled study. J Am Acad Dermatol. 2004;51(6):1002-6.

20. Hochman B, Nahas FX, Sobral CS, Arias V, Locali RF, Juliano Y, Ferreira LM. Nerve fibres: a possible role in keloid pathogenesis. Br J Dermatol. 2008;158:651-2.

21. Holavanahalli RK, Helm PA, Kowalske KJ. Long-term outcomes in patients surviving large burns: the skin. J Burn Care Res. 2010;31(4):631-9.

22. Pereira MP, Ständer S. Chronic pruritus: current and emerging treatment options. Drugs. 2017;77(9):999-1007.

23. Wulff BC, Wilgus TA. Mast cell activity in the healing wound: more than meets the eye? Exp Dermatol. 2013;22(8):507-10.
24. Twycross R, Greaves MW, Handwerker H, Jones EA, Libretto SE, Szepietowski JC, et al. Itch: scratching more than the surface. QJM. 2003;96(1):7-26.

25. Hill SJ. Distribution, properties, and functional characteristics of three classes of histamine receptor. Pharmacol Rev. 1990;42(1):45-83.

26. Lippert U, Artuc M, Grützkau A, Babina M, Guhl S, Haase I, et al. Human skin mast cells express $\mathrm{H} 2$ and $\mathrm{H} 4$, but not $\mathrm{H} 3$ receptors. J Investig Dermatol. 2004;123(1):116-23.

27. Ohkubo T, Shibata M, Inoue M, Kaya H, Takahashi H. Regulation of substance $\mathrm{P}$ release mediated via prejunctional histamine H3 receptors. Eur J Pharmacol. 1995;273:83-8.

28. Ahuja R, Chatterjee P. Postburn pruritus: a practical review. Indian J Burns. 2014;22(1):13.

29. Miyamoto T, Nojima H, Kuraishi Y. Intradermal cholinergic agonists induce itch-associated response via M3 muscarinic acetylcholine receptors in mice. Jpn J Pharmacol. 2002;88(3):351-4.

30. Grando SA, Kist DA, Qi M, Dahl MV. Human keratinocytes synthesize, secrete, and degrade acetylcholine. J Invest Dermatol. 1993;101(1):32-6.

31. Walker K, Perkins M, Dray A. Kinins and kinin receptors in the nervous system. Neurochem Int. 1995;26(1):1-16; discussion $17-26$.

32. Averbeck B, Reeh PW. Interactions of inflammatory mediators stimulating release of calcitonin gene-related peptide, substance $P$ and prostaglandin $\mathrm{E}(2)$ from isolated rat skin. Neuropharmacology. 2001;40(3):416-23.

33. Cocchiara R, Lampiasi N, Albeggiani G, Bongiovanni A, Azzolina A, Geraci D. Mast cell production of TNF-alpha induced by substance $\mathrm{P}$ evidence for a modulatory role of substance P-antagonists. J Neuroimmunol. 1999;101(2):128-36.

34. Schmelz M, Schmidt R, Bickel A, Handwerker HO, Torebjörk HE. Specific C-receptors for itch in human skin. J Neurosci. 1997;17:8003-8.

35. Andrew D, Craig AD. Spinothalamic lamina I neurones selectively responsive to cutaneous warming in cats. J Physiol. 2001;537:489-95.

36 Jinks SL, Carstens E. Superficial dorsal horn neurons identified by intracutaneous histamine: chemonociceptive responses and modulation by morphine. J Neurophysiol. 2000;84(2):616-27.

37. Drzezga A, Darsow U, Treede RD, Siebner H, Frisch M, Munz F, Weilke F, Ring J, Schwaiger M, Bartenstein P. Central activation by histamine-induced itch: analogies to pain processing: a correlational analysis of $\mathrm{O}-15 \mathrm{H} 2 \mathrm{O}$ positron emission tomography studies. Pain. 2001;92:295-305.

38. Goutos I. Neuropathic mechanisms in the pathophysiology of burns pruritus: redefining directions for therapy and research. J Burn Care Res. 2013;34(1):82-93. https://doi.org/10.1097/ BCR.0b013e3182644c44.

39. Vitale M, Fields-Blache C, Luterman A. Severe itching in the patient with burns. J Burn Care Rehabil. 1991;12(4):330-3.

40. Ahuja RB, Gupta R, Gupta G, Shrivastava P. A comparative analysis of cetirizine, gabapentin and their combination in the relief of post-burn pruritus. Burns. 2011;37(2):203-7.

41. Goutos I, Eldardiri M, Khan AA, Dziewulski P, Richardson PM. Comparative evaluation of antipruritic protocols in acute burns. The emerging value of gabapentin in the treatment of burns pruritus. J Burn Care Res. 31(1):57-63.

42. Jinks SL, Carstens E. Superficial dorsal horn neurons identified by intracutaneous histamine: chemonociceptive responses and modulation by morphine. J Neurophysiol. 2000;84:616-27.

43. Drzezga A, Darsow U, Treede R-D, Siebner H, Frisch M, Munz F, Weilke F, Ring J, Schwaiger M, Bartenstein P. Central activation by histamine-induced itch: analogies to pain processing: a correlational analysis of $\mathrm{O}-15 \mathrm{H} 2 \mathrm{O}$ positron emission tomography studies. Pain. 92(1):295-305. 
44. Malenfant A, Forget R, Amsel R, Papillon J, Frigon JY, Choinière $M$. Tactile, thermal and pain sensibility in burned patients with and without chronic pain and paresthesia problems. Pain. 1998;77(3):241-51.

45. Shlash SOA, Madani JOA, Deib JIE, Alsubhi FS, Saifi SSA, Helmi AMA, et al. Demographic characteristics and outcome of burn patients requiring skin grafts: a tertiary hospital experience. Int J Burns Trauma. 2016;6(2):30-6.

46. Goutos I. Burns pruritus - a study of current practices in the UK. Burns. 2010;36(1):42-8.

47. Bell L, McAdams T, Morgan R, Parshley PF, Pike RC, Riggs P, et al. Pruritus in burns: a descriptive study. J Burn Care Rehabil. 1998;9(3):305-8.

48. Scholzen T, Armstrong CA, Bunnett NW, Luger TA, Olerud JE, Ansel JC. Neuropeptides in the skin: interactions between the neuroendocrine and the skin immune systems. Exp Dermatol. 1998;7(2-3):81-96.

49. Ständer S, Schmelz M. Chronic itch and pain-Similarities and differences. Eur J Pain. 2006;10:473.

50. Crowe R, Parkhouse N, McGrouther D, Burnstock G. Neuropeptide-containing nerves in painful hypertrophic human scar tissue. Br J Dermatol. 1994;130(4):444-52.

51. Scott JR, Muangman PR, Tamura RN, Zhu KQ, Liang Z, Anthony $J$, et al. Substance $P$ levels and neutral endopeptidase activity in acute burn wounds and hypertrophic scar. Plast Reconstr Surg. 2005;115(4):1095-102.

52. Cheng B, Liu H-W, Fu X-B. Update on pruritic mechanisms of hypertrophic scars in postburn patients: the potential role of opioids and their receptors. J Burn Care Res. 2011;32(4):e118-5.

53. Brown BC, McKenna SP, Siddhi K, McGrouther DA, Bayat A. The hidden cost of skin scars: quality of life after skin scarring. J Plast Reconstr Aesthet Surg. 2008;61(9):1049-58.

54. Reinholz M, Poetschke J, Schwaiger H, Epple A, Ruzicka T, Gauglitz GG. The dermatology life quality index as a means to assess life quality in patients with different scar types. J Eur Acad Dermatol Venereol. 2015;29(11):2112-9.

55. Bijlard E, Kouwenberg C, Timman R, Hovius S, Busschbach J, Mureau M. Burden of Keloid disease: a cross-sectional healthrelated quality of life assessment. Acta Dermato Venereologica. 2017;97(2):225-9.

56. Bock O, Schmid-Ott G, Malewski P, Mrowietz U. Quality of life of patients with keloid and hypertrophic scarring. Arch Dermatol Res. 2006;297(10):433-8.

57. Choinière M, Melzack R, Papillon J. Pain and paresthesia in patients with healed burns: an exploratory study. J Pain Symptom Manag. 1991;6(7):437-44.

58. Schneider JC, Harris NL, El Shami A, Sheridan RL, Schulz JT, Bilodeau M-L, et al. A descriptive review of neuropathic-like pain after burn injury. J Burn Care Res. 2006;27(4):524-8.

59. Van Loey NEE, Bremer M, Faber AW, Middelkoop E, Nieuwenhuis MK. Itching following burns: epidemiology and predictors. Br J Dermatol.2007;071106220718003.

60. Carrougher GJ, Martinez EM, McMullen KS, Fauerbach JA, Holavanahalli RK, Herndon DN, Wiechman SA, Engrav LH, Gibran NS. Pruritus in adult burn survivors. J Burn Care Res. 34(1):94-101

61. Schneider JC, Nadler DL, Herndon DN, Kowalske K, Matthews K, Wiechman SA, Carrougher GJ, Gibran NS, Meyer WJ, Sheridan RL, Ryan CM. Pruritus in pediatric burn survivors. J Burn Care Res. 36(1):151-8.

62. Phan NQ, et al. J der Deutschen Dermatologischen Gesellschaft. 2011;9:148-9.

63. Blankers K, Dankerlui N, van Loey N, Pursad M, Rode H, van Dijk M. Cross-cultural validation of the itch man scale in pediatric burn survivors in a South African setting. Burns. 2019;45(3):725-31.
64. Reich A, Heisig M, Phan N, Taneda K, Takamori K, Takeuchi S, et al. Visual analogue scale: evaluation of the instrument for the assessment of pruritus. Acta Dermato Venereologica. 2012;92(5):497-501.

65. Bell PL, Gabriel V. Evidence based review for the treatment of post-burn pruritus. J Burn Care Res. 2009;30(1):55-61.

66. McKemy DD, Neuhausser WM, Julius D. Identification of a cold receptor reveals a general role for TRP channels in thermosensation. Nature. 2002;416(6876):52-8.

67. Anthonissen M, Daly D, Janssens T, Van den Kerckhove E. The effects of conservative treatments on burn scars: a systematic review. Burns. 2016;42(3):508-18.

68. Klotz T, Kurmis R, Munn Z, Heath K, Greenwood J. Moisturisers in scar management following burn: a survey report. Burns. 2017;43(5):965-72.

69. Harte D, Gordon J, Shaw M, Stinson M, Porter-Armstrong A. The use of pressure and silicone in hypertrophic scar management in burns patients: a pilot randomized controlled trial. J Burn Care Res. 2009;30(4):632-42.

70. Ogawa R, Hyakusoku H, Ogawa K, Nakao C. Effectiveness of mugwort lotion for the treatment of post-burn hypertrophic scars. J Plast Reconstr Aesthet Surg. 2008;61(2):210-2.

71. Nedelec B, Rachelska G, Parnell LKS, LaSalle L. Double-blind, randomized, pilot study assessing the resolution of postburn pruritus. J Burn Care Res. 2012;33(3):398-406.

72. Lewis PA, Wright K, Webster A, Steer M, Rudd M, Doubrovsky A, Gardner G. A randomized controlled pilot study comparing aqueous cream with a beeswax and herbal oil cream in the provision of relief from postburn pruritis. J Burn Care Res. 33(4):e195-200.

73. Phillips TJ, Gerstein AD, Lordan V. A randomized controlled trial of hydrocolloid dressing in the treatment of hypertrophic scars and keloids. Dermatol Surg. 1996;22(9):775-8.

74. Hoeksema H, De Vos M, Verbelen J, Pirayesh A, Monstrey S. Scar management by means of occlusion and hydration: a comparative study of silicones versus a hydrating gel-cream. Burns. 2013;39(7):1437-48.

75. Field T, Peck M, et al. Postburn itching, pain, and psychological symptoms are reduced with massage therapy. J Burn Care Rehabil. 2000;21(3):189-93.

76. Roh YS, Cho H, Oh JO, Yoon CJ. Effects of skin rehabilitation massage therapy on pruritus, skin status, and depression in burn survivors. Taehan Kanho Hakhoe Chi. 2007;37(2):221-6.

77. Ahuja RB, Gupta GK. A four arm, double blind, randomized and placebo controlled study of pregabalin in the management of post-burn pruritus. Burns. 2013;39(1):24-9.

78. Gürol AP, Polat S, Akçay MN. Itching, pain, and anxiety levels are reduced with massage therapy in burned adolescents. J Burn Care Res. 31(3):429-32.

79. Schachner L, Field T, Hernandez-Reif M, Duarte AM, Krasnegor J. Atopic dermatitis symptoms decreased in children following massage therapy. Pediatr Dermatol. 2009;15(5):390-5.

80. Field T, Peck M, Krugman S, Tuchel T, Schanberg S, Kuhn C, et al. Burn injuries benefit from massage therapy. J Burn Care Rehabil. 1998;19(3):241-4.

81. Musgrave MA, Umraw N, Fish JS, Gomez M, Cartotto RC The effect of silicone gel sheets on perfusion of hypertrophic burn scars. J Burn Care Rehabil 23:208-1481

82. Quinn KJ, Evans JH, Courtney JM, Gaylor JDS, Reid WH. Non-pressure treatment of hypertrophic scars. Burns. 1985;12:102-8.

83. Chan KY, Lau CL, Adeeb SM, Somasundaram S, Nasir-Zahari M. A randomized, placebo-controlled, double-blind, prospective clinical trial of silicone gel in prevention of hypertrophic scar development in median sternotomy wound. Plast Reconstr Surg. 2005;116(4):1013-20; discussion 1021-2. 
84. van der Wal MBA, van Zuijlen PP, van de Ven P, Middelkoop E. Topical silicone gel versus placebo in promoting the maturation of burn scars: a randomized controlled trial. Plast Reconstr Surg. 2010;126(2):524-31.

85. Momeni M, Hafezi F, Rahbar H, Karimi H. Effects of silicone gel on burn scars. Burns. 2009;35(1):70-4.

86. Eishi K, Bae S, Ogawa F, Hamasaki Y, Shimizu K, Katayama I. Silicone gel sheets relieve pain and pruritus with clinical improvement of keloid: possible target of mast cells. J Dermatol Treat. 2003;14(4):248-52.

87. Li-Tsang CWP, Lau JCM, Choi J, Chan CCC, Jianan L. A prospective randomized clinical trial to investigate the effect of silicone gel sheeting (Cica-Care) on post-traumatic hypertrophic scar among the Chinese population. Burns. 2006;32(6): 678-83.

88. Wittenberg GP, Fabian BG, Bogomilsky JL, Schultz LR, Rudner EJ, Chaffins ML, et al. Prospective, single-blind, randomized, controlled study to assess the efficacy of the 585 -nm flashlamppumped pulsed-dye laser and silicone gel sheeting in hypertrophic scar treatment. Arch Dermatol. 1999;135(9):1049-55.

89. Sproat JE, Dalcin A, Weitauer N, Roberts RS. Hypertrophic sternal scars: silicone gel sheet versus Kenalog injection treatment. Plast Reconstr Surg. 1992;90(6):988-92.

90. Hettrick HH, O'Brien K, Laznick H, Sanchez J, Gorga D, Nagler W, et al. Effect of transcutaneous electrical nerve stimulation for the management of burn pruritus: a pilot study. $\mathrm{J}$ Burn Care Rehabil. 2004;25(3):236-40.

91. Choiniere M, Papillon J. Topical capsaicin treatment for postburn pruritus: a double blind study. In: Abstract: 9th Congress of the International Society for Burn Injuries; 2001.

92. Hercogová J. Topical anti-itch therapy. Dermatol Ther. 18(4):341-3.

93. Stan̈der S, Steinhoff M, Schmelz M, et al. Neurophysiology of pruritus: cutaneous elicitation of itch. Arch Dermatol. 2003;139:1463-70.

94. Simons FER. Advances in $\mathrm{H}_{1}$-antihistamines. N Engl J Med. 2004;351(21):2203-17.

95. Simons FER. H1-antihistamines: more relevant than ever in the treatment of allergic disorders. J Allergy Clin Immunol. 2003;112(4 Suppl):S42-52.

96. Vitale M, Fields-Blache C, Luterman A. Severe itching in the patient with burns. J Burn Care Rehabil. 1991;12(4):330-3. https://doi.org/10.1097/00004630-199107000-00008.

97. Rowbotham M, Harden N, Stacey B, Bernstein P, Magnus-Miller L. Gabapentin for the treatment of postherpetic neuralgia: a randomized controlled trial. JAMA. 1998;280(21):1837-42.

98. Gee NS, Brown JP, Dissanayake VU, Offord J, Thurlow R, Woodruff GN. The novel anticonvulsant drug, gabapentin (Neurontin), binds to the alpha2delta subunit of a calcium channel. J Biol Chem. 1996;271(10):5768-76.

99. Kuzniecky R, Ho S, Pan J, Martin R, Gilliam F, Faught E, et al. Modulation of cerebral GABA by topiramate, lamotrigine, and gabapentin in healthy adults. Neurology. 2002;58(3):368-72.

100. Conway H, Stark RB. ACTH in plastic surgery. Plast Reconstr Surg (1946). 1951;8(5):354-77.

101. Mustoe TA, Cooter RD, Gold MH, et al. International clinical recommendations on scar management. Plast Reconstr Surg. 2002;110(2):560-71. https://doi.org/10.1097/00006534200208000-00031.

102. Gold MH, Berman B, Clementoni MT, Gauglitz GG, Nahai F, Murcia C. Updated international clinical recommendations on scar management: part 1-evaluating the evidence. Dermatol Surg. 2014;40(8):817-24.

103. Darzi MA, Chowdri NA, Kaul SK, Khan M, Wood M, Rollins C. Evaluation of various methods of treating keloids and hypertrophic scars: a 10-year follow-up study. Br J Plast Surg. 1992;45(5):374-9.

104. Manuskiatti W, Fitzpatrick RE. Treatment response of keloidal and hypertrophic sternotomy scars comparison among intralesional corticosteroid, 5-fluorouracil, and 585-nm flashlamp-pumped pulsed-dye laser treatments. Arch Dermatol. 2002;138(9):1149-55.

105. Boutli-Kasapidou F, Tsakiri A, Anagnostou E, Mourellou O. Hypertrophic and keloidal scars: an approach to polytherapy. Int J Dermatol. 2005;44(4):324-7.

106. Tan E, Chua S, Lim J. Topical silicone gel sheet versus intralesional injections of triamcinolone acetonide in the treatment of keloids - a patient-controlled comparative clinical trial. J Dermatol Treat. 1999;10(4):251-4.

107. Martin MS, Collawn SS. Combination treatment of $\mathrm{CO}$ fractional laser, pulsed dye laser, and triamcinolone acetonide injection for refractory keloid scars on the upper back. J Cosmet Laser Ther. 2013;15(3):166-70.

108. Goutos I, Ogawa R. Steroid tape: a promising adjunct to scar management. Scars Burns Healing. 2017;3:2059513117690937.

109. Wright G, Lax A, Mehta SB. A review of the longevity of effect of botulinum toxin in wrinkle treatments. Br Dent $\mathrm{J}$. 2018;224(4):255-60.

110. Sohrabi C, Goutos I. The use of botulinum toxin in keloid scar management: a literature review [Internet]. National Plastic Surgery Research Forum; 2019 [cited 2019 Aug 1]. Available from: https://nationalplasticsurgeryresearchforum.org/the-use-of-botulinum-toxin-in-keloid-scar-management-a-literature-review.

111. Shaarawy E, Hegazy RA, Abdel Hay RM. Intralesional botulinum toxin type A equally effective and better tolerated than intralesional steroid in the treatment of keloids: a randomized controlled trial. J Cosmet Dermatol. 2015;14(2):161-6.

112. Rasaii S, Sohrabian N, Gianfaldoni S, Hadibarhaghtalab M, Pazyar N, Bakhshaeekia A, et al. Intralesional triamcinolone alone or in combination with botulinium toxin $\mathrm{A}$ is ineffective for the treatment of formed keloid scar: a double blind controlled pilot study. Dermatol Ther. 2019;32(2):e12781.

113. Li J, Wu X-Y, Chen X-D. Observation on clinical efficacy of intralesional injection of glucocorticoid combined with botulinum toxin type A for treatment of keloid | J Li. J Clin Dermatol. 2017;46(9):629-32.

114. Akhtar N, Brooks P. The use of botulinum toxin in the management of burns itching: preliminary results. Burns. 2012;38(8):1119-23.

115. Gregoire FM, Smas CM, Sul HS. Understanding adipocyte differentiation. Physiol Rev. 1998;78:783-809 103.

116. Conde-Green A, Baptista LS, de Amorin NFG, de Oliveira ED, da Silva KR, Pedrosa CDSG, Borojevic R, Pitanguy I. Effects of centrifugation on cell composition and viability of aspirated adipose tissue processed for transplantation. Aesthet Surg J. 2010;30(2):249-55.

117. Klinger M, Lisa A, Klinger F, Giannasi S, Veronesi A, Banzatti B, et al. Regenerative approach to scars, ulcers and related problems with fat grafting. Clin Plast Surg. 2015;42(3): 345-52.

118. Cheville AL, Sloan JA, Northfelt DW, Jillella AP, Wong GY, Bearden JD III, et al. Use of a lidocaine patch in the management of postsurgical neuropathic pain in patients with cancer: a phase III double-blind crossover study (N01CB). Support Care Cancer. 2009;17(4):451-60.

119. Fredman R, Edkins RE, Hultman CS. Fat grafting for neuropathic pain after severe burns. Ann Plast Surg. 2016;76:S298-303.

120. Huang S-H, Wu S-H, Chang K-P, Lin C-H, Chang C-H, Wu $\mathrm{Y}-\mathrm{C}$, et al. Alleviation of neuropathic scar pain using autologous fat grafting. Ann Plast Surg. 2015;74:S99-104. 
121. Condé-Green A, Marano AA, Lee ES, Reisler T, Price LA, Milner SM, Granick MS. Fat grafting and adipose-derived regenerative cells in burn wound healing and scarring. Plast Reconstr Surg. 2016;137:302-312116.

122. Negenborn VL, Groen J-W, Smit JM, Niessen FB, Mullender MG. The use of autologous fat grafting for treatment of scar tissue and scar-related conditions. Plast Reconstr Surg. 2016;137:31e-43e.

123. Elsaie ML, Choudhary S. Lasers for scars: a review and evidence-based appraisal. J Drugs Dermatol. 2010;9:1355-62.

124. Chrastil B, Glaich AS, Goldberg LH, Friedman PM. Secondgeneration 1,550-nm fractional photothermolysis for the treatment of acne scars. Dermatol Surg. 2008;34(10):1327-32.

125. Anderson RR, Parrish JA. Selective photothermolysis: precise microsurgery by selective absorption of pulsed radiation. Science. 1983;220(4596):524-7.

126. Nakagawa H, Tan OT, Parrish JA. Ultrastructural changes in human skin after exposure to a pulsed laser. J Invest Dermatol. 1985;84(5):396-400.

127. Ebid AA, Ibrahim AR, Omar MT, El Baky AMA. Long-term effects of pulsed high-intensity laser therapy in the treatment of post-burn pruritus: a double-blind, placebo-controlled, randomized study. Lasers Med Sci. 2017;32(3):693-701.
128. Vasheghani MM, Bayat M, Rezaei F, Bayat A, Karimipour M. Effect of low-level laser therapy on mast cells in seconddegree burns in rats. Photomed Laser Surg. 2008;26(1): $1-5$.

129. Peplow PV, Chung T-Y, Baxter GD. Application of low level laser technologies for pain relief and wound healing: overview of scientific bases. Phys Ther Rev. 2010;15(4):253-85.

130. Lim W, Lee S, Kim I, Chung M, Kim M, Lim H, et al. The anti-inflammatory mechanism of $635 \mathrm{~nm}$ light-emitting-diode irradiation compared with existing COX inhibitors. Lasers Surg Med. 2007;39(7):614-21.

131. Chow R, Armati P, Laakso E-L, Bjordal JM, Baxter GD. Inhibitory effects of laser irradiation on peripheral mammalian nerves and relevance to analgesic effects: a systematic review. Photomed Laser Surg. 2011;29:365-81.

132. Alster TS, Williams CM. Treatment of keloid sternotomy scars with $585 \mathrm{~nm}$ flashlamp-pumped pulsed-dye laser. Lancet. 1995;345(8959):1198-200.

133. Douglas H, Lynch J, Harms K-A, Krop T, Kunath L, van Vreeswijk C, McGarry S, Fear MW, Wood FM, Murray A, Rea S. Carbon dioxide laser treatment in burn-related scarring: a prospective randomised controlled trial. J Plastic Reconst Aesthet Surg. 2019;72(6):863-70.

Open Access This chapter is licensed under the terms of the Creative Commons Attribution 4.0 International License (http://creativecommons. org/licenses/by/4.0/), which permits use, sharing, adaptation, distribution and reproduction in any medium or format, as long as you give appropriate credit to the original author(s) and the source, provide a link to the Creative Commons license and indicate if changes were made.

The images or other third party material in this chapter are included in the chapter's Creative Commons license, unless indicated otherwise in a credit line to the material. If material is not included in the chapter's Creative Commons license and your intended use is not permitted by statutory regulation or exceeds the permitted use, you will need to obtain permission directly from the copyright holder.

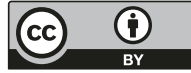

